\title{
Maintenance of old-growth size structure and fecundity of the red rock lobster Jasus edwardsii among marine protected areas in Fiordland, New Zealand
}

\author{
Lucy Jack*, Stephen R. Wing \\ Department of Marine Science, 310 Castle Street, University of Otago, Dunedin, New Zealand
}

\begin{abstract}
Persistence of long-lived coastal species depends on the maintenance of mature age distributions of reproductive individuals at the landscape scale. We investigated patterns in abundance and size structure of the red rock lobster Jasus edwardsii across a network of marine protected areas in Fiordland, New Zealand. Abundance of J. edwardsii across 53 sites in 2006-2007 was highest in marine reserves established in 1993 and comparatively low in reserves and commercial exclusion zones established in 2005 and in commercially fished regions. Within the Doubtful-Bradshaw Sound complex, we observed a high abundance of lobsters at Te Awaatu Channel marine reserve (est. 1993), intermediate abundances in the commercial exclusion zone and within Kutu Parera marine reserve (est. 2005), but no lobsters in Taipari Roa marine reserve (est. 2005), where habitat quality was degraded. We used an accurate and precise videogrammetric technique to non-invasively measure size structure of lobsters within each reserve and compared this new method with established techniques. Sex ratios were determined and an estimate of fecundity per unit area was calculated for each reserve. Results indicate that within the Doubtful-Bradshaw Sound complex the reproductive contribution of lobsters per unit area from the marine reserve at Te Awaatu Channel was significantly greater than that at Taipari Roa, while that from the commercial exclusion zone and Kutu Parera were intermediate. These data highlight the importance of marine reserves encompassing high quality habitats for maintaining optimal reproductive potential of red rock lobster populations by harbouring high abundances and mature size distributions at the landscape scale.
\end{abstract}

KEY WORDS: Fiordland · Video $\cdot$ Habitat quality · Marine reserve $\cdot$ Survey bias $\cdot$ Visual census · Population structure

Resale or republication not permitted without written consent of the publishe

\section{INTRODUCTION}

Spatially explicit management strategies, in particular no-take marine reserves, are an increasingly applied tool for conservation of biodiversity and marine resources (Quinn et al. 1993, Palumbi 2001) and enhancement of fished stocks (Dayton et al. 2000, Roberts et al. 2001). While optimal designs and potential benefits of marine reserves are a contentious topic (e.g. Roberts \& Polunin 1991, Russ \& Alcala 1996, Allison et al. 1998), the benefits of protecting a mature portion of the spawning population are clear from bioeco- nomic (Hastings \& Botsford 1999) and empirical studies (Halpern 2003). These studies highlight the importance of maintaining spawning populations comprising large, mature individuals (Berkeley et al. 2004). Marine protected areas, especially marine reserves, play a key role in maintenance of old growth age structure by providing refuges for productive spawning stocks of exploited fish (Berkeley et al. 2004, Birkeland \& Dayton 2005) and invertebrates (Quackenbush 1994, Rogers-Bennett \& Leaf 2006). Inside marine reserves, populations are able to increase in size, and individuals can live longer, grow larger and develop increased 
reproductive potential. Likely benefits to adjacent fisheries include a net emigration of adults and juveniles and the pelagic export of eggs or larvae.

Many populations of exploited marine species consist of relatively sedentary adults spread across large geographic regions connected by larval dispersal, and to a lesser degree, by movement of adults (Kritzer \& Sale 2006). The subdivided nature of these populations means that local environmental forcing of vital rates (recruitment, mortality, growth and movement) can influence source-sink dynamics and persistence of metapopulations on a regional scale (Botsford et al. 1998, Wing et al. 2003, Sanford \& Menge 2007). Consequently, spatial management can be improved by the application of networks of protected areas at the regional scale, within which landscape-scale processes, such as connectivity among food webs (McLeod \& Wing 2007, Salomon et al. 2008, Wing et al. 2008) and source-sink structure (Fogarty 1999, Wing 2010), are maintained. The placement of marine reserve boundaries within this metapopulation landscape is at the crux of a network's capacity to encompass patches whose size and connectivity are sufficient to enable regional population persistence (MacArthur \& Wilson 1967, Hanski \& Gyllenberg 1993, Claudet et al. 2008). A critical feature of this requirement is to include habitat of sufficient quality to sustain high biomass and mature size structure of exploited species (Root 1998, Fogarty 1999, Lindholm et al. 2001, Fleishman et al. 2002, Rodwell et al. 2003).

In the adaptive management process, assessment of the functionality of marine reserve networks requires rigorous enumeration of community parameters, including relative densities and sizes of exploited species, for comparison over time and among management units. Implicit in these studies is a reliable means of quantifying size structure as well as abundance of protected stocks in order to assess their contribution to reproductive output of the regional population. The accuracy of the sampling method used to collect field data directly affects the degree of statistical inference possible. Inadequate or biased sampling methodology and survey design create difficulty in effectively measuring reserve effects and predicting outcomes of reserve implementation.

Most commonly, attempts to enumerate fish and invertebrates in this context have used underwater visual census (UVC) methods (e.g. MacDiarmid \& Breen 1992, English et al. 1994, Willis et al. 2003, Pande et al. 2008). However, surveys involving direct observations made by divers are susceptible to bias associated with observer experience and subjective decision making, even when previous experience is relatively extensive (>100 h) (Willis et al. 2000, Edgar et al. 2004). Although constant or known biases can be accommodated statistically, misleading interpretations of data patterns are likely if this bias is inconsistent over time or space, or if variance in data quality exists among recorders (Harvey 2000, Edgar et al. 2004, Edgar \& Stewart-Smith 2009).

Subjectivity in length estimation of free-ranging animals can be overcome using photogrammetric calibration techniques. Diver- or remotely operated underwater video using stereo-image measurements are increasingly utilised for measuring fish abundances and lengths (Shortis et al. 2009). However, these methods may be unsuitable for cryptic animals that are not easily attracted to bait and are too cumbersome to use in complex relief such as amongst boulders or in crevices. In this context, diver-operated video-mounted lasers offer an objective method for length estimation whereby images are scaled by measuring the distance between fucidal marks. The availability of inexpensive and powerful lasers and advent of user-friendly freeware for digital videography make laser-scaled photogrammetry a cost-effective and time-efficient method for obtaining accurate and precise remote measurements (Gingras et al. 1998, Love et al. 2000, Rochet et al. 2003, Bergeron 2007). In the present study, we describe a novel videogrammetric technique for size estimation of red rock lobsters Jasus edwardsii in order to inform the adaptive management process in Fiordland, on the southwest coast of the South Island, New Zealand.

Assessment of the spatial overlap of management units and population structure is especially important in topographically complex regions such as Fiordland, where the glacially carved fjords form a succession of 15 embayments containing an insular and fragmented array of marine habitats (Fig. 1). Within each fjord, strong gradients in light, salinity and wave action along the fjord axis drive spatial variability in benthic primary production (Cornelisen et al. 2007, Wing et al. 2007). On the wave-washed outer coast, benthic productivity is dominated by abundant kelp forests, whilst in the quiescent habitat of the inner fjord, forest litter and estuarine seaweeds dominate the carbon pool (McLeod \& Wing 2007, Wing et al. 2008). The resultant gradient in the quality and quantity of food sources for benthic feeding organisms is the basis for strong bottom-up control of growth and reproductive output of the sea urchin Evechinus chloroticus (Wing 2009) and for plasticity in diet in holothurians (Australostichopus mollis) (Wing et al. 2008), reef fish such as blue cod Parapercis colias and sea perch Helicolenus percoides (Rodgers \& Wing 2008, R. Lawton et al. unpubl. data) and the red rock lobster Jasus edwardsii (Jack et al. 2009).

Red rock lobsters are of great cultural and economic significance in New Zealand and comprise the most valuable inshore fishery (NZ\$ 1.35 billion in 2007, New 


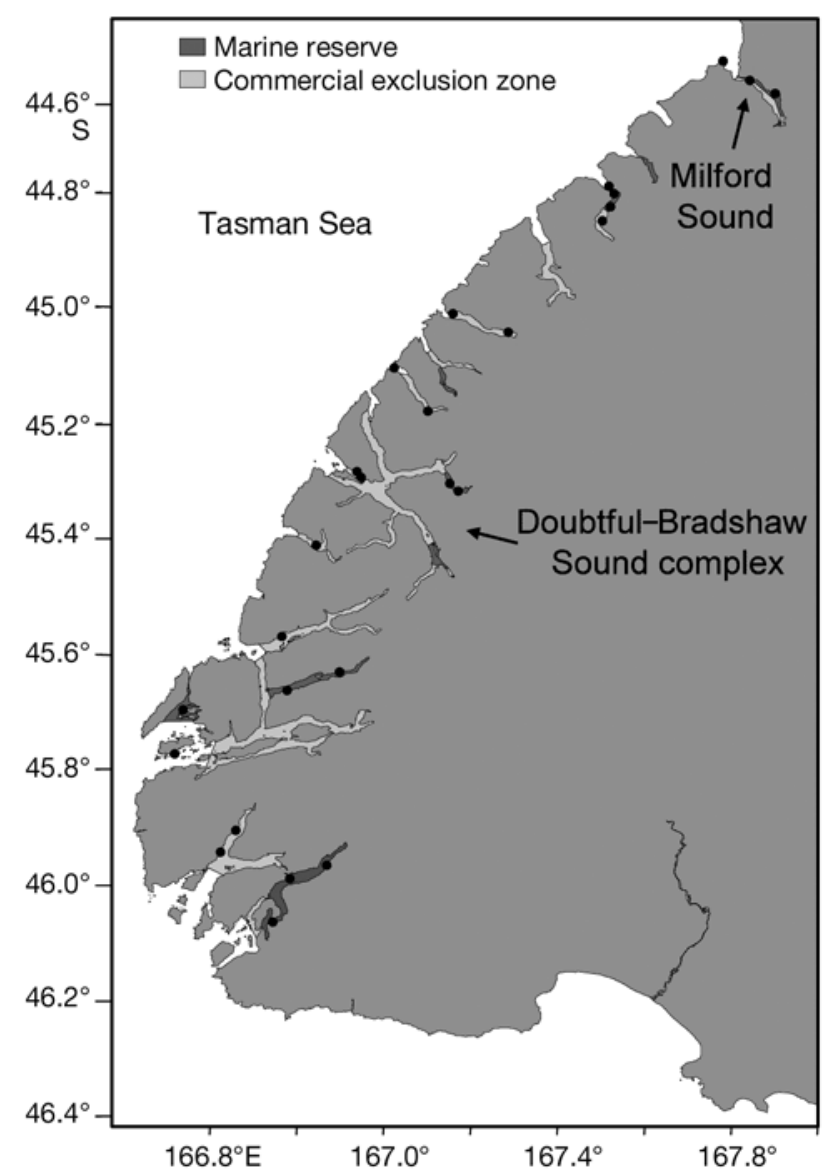

Fig. 1. Fiordland, New Zealand. (•): study sites. Commercial exclusion zone: light grey. Marine reserves: dark grey

Zealand Rock Lobster Industry Council). Due to their relatively large size, high abundance and wide distribution, red rock lobsters are ecologically significant predators, driving the top-down structuring of invertebrate prey on New Zealand rocky reefs (Witman \& Grange 1998, Shears \& Babcock 2002) and in adjacent soft sediments (Langlois et al. 2005). Although Fiordland is considered a relatively pristine natural environment, populations of red rock lobsters have suffered localised depletion in the inner fjords (Annala 1993) and are a remnant of their natural ecological condition region-wide, with fisheries scientists estimating that approximately $3 \%$ virgin biomass remains in the Fiordland region including Stewart Island (Starr \& Bentley 2002). In addition to fishing pressure, Fiordland has been subject to localised habitat conversion. Physical habitat and community structure have changed significantly in the inner reaches of Doubtful Sound as a consequence of the input of freshwater from the Manapouri hydroelectric power station (Bantham 1965, Boyle et al. 2001, Tallis et al. 2004, Rutger
\& Wing 2006). Extended exposure to freshwater in this region has resulted in severe depletion of bivalves (Rutger \& Wing 2006, McLeod \& Wing 2008), which are an important prey item for red rock lobsters (Witman \& Grange 1998, Jack et al. 2009).

In 1993, 2 no-take marine reserves were established in Fiordland: Te Awaatu Channel (The Gut) marine reserve in the semi-wave-exposed habitat at the entrance to Doubtful Sound, and Piopiotahi (Milford Sound) marine reserve, along the northern axis of Milford Sound (Fig. 1). More recently, the Fiordland Marine Management Act 2005 (Te Moana o Atawhenua; FMMA) closed inner-fjord waters to commercial fishing and reduced bag limits for recreational take (11363.7 ha region wide or $59 \%$ of the inner-fjord area) and established a network of 8 new marine reserves, nested within the commercial exclusion zones (CEZs), bringing the total no-take area to 10421 ha or $13.5 \%$ of the total inner-fjord area (Fig. 1). By controlling mortality due to fishing, the new spatially explicit management regime will likely allow for increases in abundance and maturity in size structure of heavily exploited species such as Jasus edwardsii, resulting in greater reproductive output for populations in Fiordland (Kelly et al. 2000, Pande et al. 2008).

The Fiordland marine system and the newly implemented network of marine protected areas present 2 interesting questions: (1) How do region-wide patterns in red rock lobster abundance overlap with the established and new network of marine protected areas? (2) And what is the potential relative contribution of populations contained in different management zones to regional egg production? In the present study, we used an extensive survey of red rock lobster populations across Fiordland to address the first question. Further, we tested a diver-operated videogrammetric technique to reliably and accurately measure the size structure of red rock lobster populations and compared this method to concurrently collected UVC data. We then applied the videogrammetric technique to a case study in the Doubtful-Bradshaw Sound complex where size and abundance data were combined to compare estimates of potential reproductive output among management units. The resulting increased resolution of spatial variability in red rock lobster population structure was used to critically appraise the likely consequences of the marine reserves implemented in the region in terms of the populations' reproductive capacity.

\section{MATERIALS AND METHODS}

Fiordland-wide abundance of red rock lobster. In January-February 2006 and 2007, red rock lobster densities were recorded using UVC at 26 sites (Fig. 1) 
throughout Fiordland, using 2 diver pairs and 1 observer per pair. Care was taken to survey comparable rock wall habitat, each site being on a slope between 90 and $45^{\circ}$ and with abundant crevices and ledges offering suitable red rock lobster shelter. Belt transects (1 per site in 2006, 3 per site in 2007), measuring $50 \times$ $5 \mathrm{~m}$, were placed horizontally along rock walls at $15 \mathrm{~m}$ depth. Transects were initially placed randomly and subsequently revisited. Caves and crevices were thoroughly searched using a dive light. To meet the normality assumptions of ANOVA, a $\ln (x+1)$-transformation was performed on the data to increase normality and homogeneity of variance. Variability in abundance among management zones was then analyzed using a nested ANOVA, with site nested within the 4 management zones (commercial exclusion zone, marine reserves est. 1993, marine reserves est. 2005 and open regions). A post hoc Tukey's test was used for pairwise comparisons.

Estimating carapace length. In a diver's presence, Jasus edwardsii typically back into a crevice and face the diver head on. Therefore, viewing the long-axis orientation of a lobster for measurement of carapace length is difficult. To overcome this problem, we measured the distance between the visually prominent supra-orbital spines (Fig. 2a, b) and developed a regression equation to derive estimates of carapace length (CL), the distance between the tip of the rostral spine and the back of the carapace on its dorsal surface.

In 2006 and 2007 a total of 456 commercially caught (approx. >100 mm CL) lobsters, and 142 hand-caught lobsters of sub-legal size $(<100 \mathrm{~mm} \mathrm{CL})$ were measured at the Fiordland lobster processing depot, Milford Sound, and the Portobello Marine Laboratory, Otago, respectively. This size range of lobsters covered the full range of sizes encountered in our subtidal surveys and provided adequate replication for each size class in the observed size distributions. Measurements to the nearest $\mathrm{mm}$ were made of the distance between the supra-orbital spines (SOS) and CL using Vernier calipers. The sex of each animal was also recorded for mature animals $(\mathrm{n}=462)$. As morphometric relationships may differ between sexes (Fairbairn 1997), an ANOVA was performed using the model CL $=$ SOS + sex $+($ SOS $\times$ sex $)$. No interaction was detected at the $\mathrm{p}=0.001$ level, thus data were pooled for further analysis.

A linear regression analysis was conducted using the variables SOS and CL. Data were selected from inside the $80 \%$ confidence interval of the regression, omitting 3 outliers that proved to have malformed or broken SOS. Using the selected data, a further regression equation was formed that predicted CL from SOS. To ascertain the reliability of the equation in predicting $\mathrm{CL}$, the SOS and CL of a further 30 captive animals
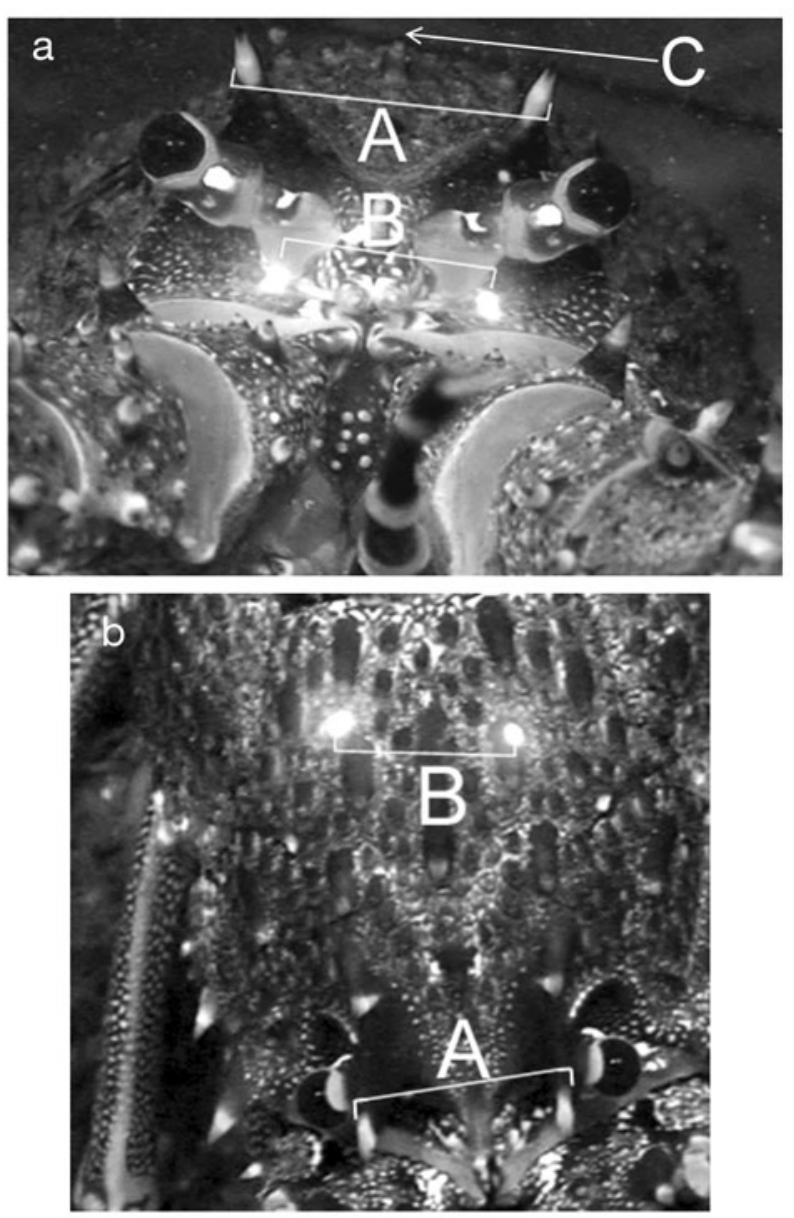

Fig. 2. Jasus edwardsii. Images captured from video using videogrammetry. Fucidal marks on the (a) frontal and (b) dorsal aspect of the lobster. A: distance between the supra orbital spines; B: distance between the fucidal marks; C: central cephalic spine

were measured using Vernier calipers. The measured (true) CL was compared to the predicted values with a pairwise $t$-test.

Videogrammetry. Assembly and testing: The system consisted of parallel lasers mounted on an underwater video housing. Two $5 \mathrm{~mW}$ red focusable laser diode modules (Calpac Lasers) were housed in a precision milled aluminium block, encased in a waterproof aluminium housing that also contained 4 AA batteries and a normally open reed switch. The laser housing was mounted on a bracket so that its orientation could be adjusted in the vertical plane. The bracket was mounted across the video housing (Top Dawg 2, Top Dawg) using existing fixtures. The lasers were mounted $17 \mathrm{~mm}$ apart, parallel to and equidistant from the optical lens of the video camera (Sony HDR-HC7 1080i HDV camcorder, with 3.2 megapixel CMOS sensor). Fucidal marks were projected onto each lob- 
ster while filming and images of the complete frontal or dorsal aspect of lobsters and both fucidal marks were recorded (Fig. 2a,b). Video footage was processed using iMovie HD 08 and images were excised as TIFF files using Grab 1.4 (93.1) (Apple Computer). Images were individually measured using the marquee tool in ImageJ 1.36b (National Institutes of Health).

The lasers were checked for deviation from parallelism at distances of up to $4 \mathrm{~m}$ by projecting marks onto graph paper before and after each video event. The system was assessed for field curvature, which distorts the relative distance between points across the image, using Andromedia Lens-doc filter (Andromedia Software) in Photoshop 7.0 (Adobe Systems) on graph paper images. No curvature was detected.

Parallax error occurs due to deviation from parallel of the orientation of the frontal axis of the subject in relation to the optical lens of the camera. It is a major source of variance in photogrammetric techniques, resulting in distance estimates that are negatively biased relative to the distance between the fucidal marks (Rochet et al. 2003, Durban \& Parsons 2006, Bergeron 2007). The central cephalic spine (Fig. 2a) was used to assess the angle of presentation and images were rejected for analysis if the spine was not shown as $>95 \%$ equidistant between the 2 SOSs.

The measurement error, or variability of repeated measurements taken on the same individual relative to variability among individuals in a particular group, was estimated for field-collected data. Percentage measurement error (\%ME) was calculated as the percent of the total variability in CL due to within-individual variation (Bailey \& Byrnes 1990). In October 2007 , 60 lobsters were filmed by divers in the DoubtfulBradshaw Sound complex and 3 images of each animal were measured. The variance and covariance of the estimates of CL was partitioned into among- and within-individual components after Bailey \& Byrnes (1990) and the \%ME was calculated.

Because accuracy of measurements made with photogrammetry may improve with operator experience (Harvey 2000), we evaluated the effect of experience on estimates of carapace length. Thirty-two videogrammetric images of lobsters were measured by the author (L.J.) and by a volunteer who was new to the method. The 2 data sets were compared using a paired t-test.

Comparison of visual estimates: In February 2007 and 2008, CL of 577 lobsters was estimated by divers by UVC at 20 sites in Fiordland. Divers categorized lobsters into 3 size classes: <100, 100 to 150 and $>150 \mathrm{~mm}$. During the same underwater surveys, another diver recorded sizes of lobsters using the videogrammetric system, in the same vicinity and for the same time period as the UVC. These images were processed to obtain photogrammetric estimates of 446 lobsters and were categorised into the same size classes for comparative analysis. A 2-sample KolmogorovSmirnov goodness-of-fit (K-S) test was used to compare the 2 data sets within each year.

Red rock lobster population structure. In February 2008, red rock lobster densities were recorded at 8 sites in the Doubtful-Bradshaw Sound complex using the same UVC method. Three $50 \times 5 \mathrm{~m}$ belt transects were sampled per site. Two sites were located in each of the 3 marine reserves and 2 sites were located in the outer-fjord CEZ region of the Doubtful-Bradshaw Sound complex (Fig. 3). The CEZ region sampled and the Te Awaatu Channel marine reserve are situated in outer-fjord habitat, whilst the Kutu Parera and Taipari Roa marine reserves are situated in inner-fjord habitat (Cornelisen et al. 2007, Wing et al. 2008). Taipari Roa marine reserve is situated in the degraded region of the fjord (Tallis et al. 2004, McLeod \& Wing 2008, Jack et al. 2009). The size and sex of lobsters were recorded using the videogrammetric method concurrently with abundance surveys at each site. Sex of each lobster was recorded on the video footage by a hand signal

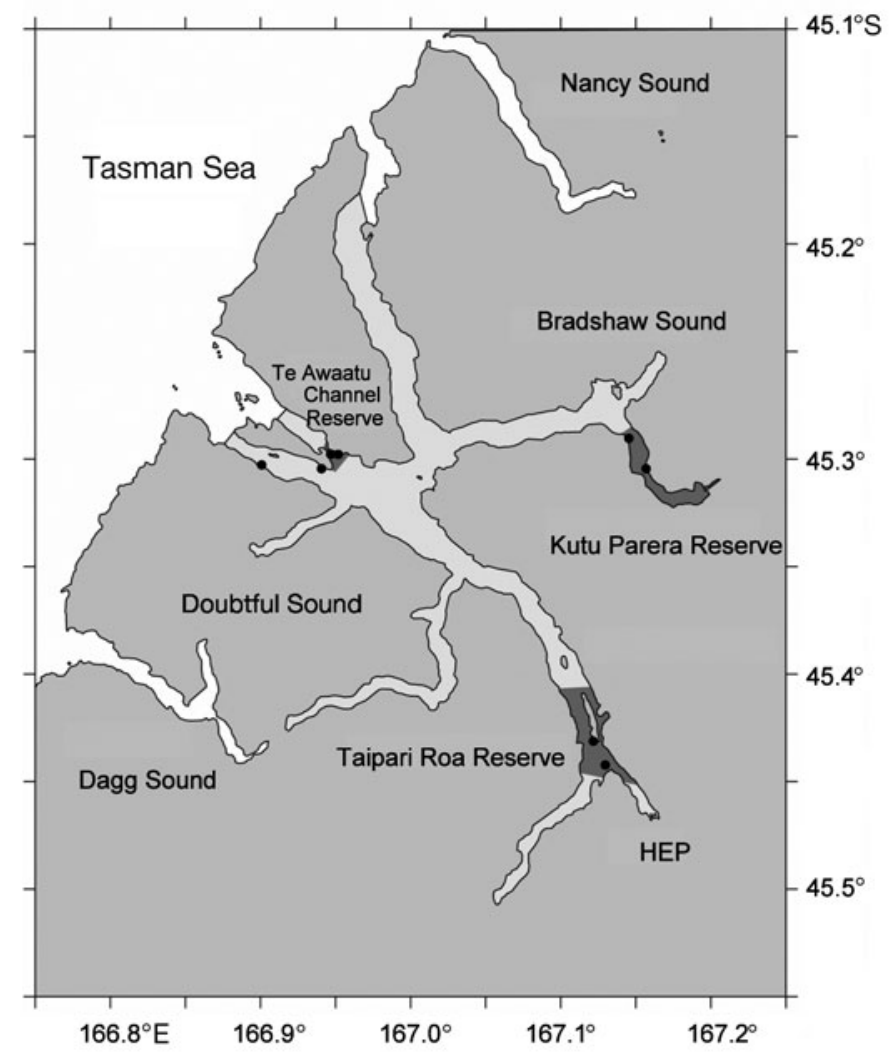

Fig. 3. Doubtful-Bradshaw Sound region of Fiordland, New Zealand. (•): study sites. Commercial exclusion zone: light grey. The 3 marine reserves: dark grey. HEP: outlet of the Manapouri hydroelectric power plant 
from the diver after visual inspection of the fifth pereiopod (terminal walking leg), which in females only is subchelate. Sex was determined for $93 \%$ of the sampled lobsters. Distribution of lobsters at the sites was highly patchy, so that at some sites there was not sufficient time to measure all lobsters on a transect, whilst at others there were not enough lobsters per transect to reliably estimate a sex ratio or size distribution. To account for this, size and sex estimation was not area stratified, but was restricted to the total number of lobsters that were measurable located within $150 \mathrm{~m}$ of the site marker ( 3 transect lengths) at $15 \mathrm{~m}$ depth during 1 dive. We took care to avoid selectivity with either technique by measuring all lobsters encountered along each transect. This method assumes that when combining size and sex with UVC (abundance) data, because both are random samples of the population, the 2 data sets are compatible and represent the same population, consistent with our sampling design.

No lobsters were observed in the Taipari Roa marine reserve. At the 6 sites where lobsters were observed, they were assigned to $5 \mathrm{~mm}$ bins following videometric calculations and size-frequency distributions of male and of female lobsters were compared among the 3 management zones. For each site, we calculated the relative abundance of males and females in each size class by combining videogrammetric (size and sex) and abundance data. Because there were a low number of sites per management unit $(\mathrm{n}=2)$, we used PERMANOVA+ for Primer (PRIMER-E) to test for among-unit differences. For each sex, we calculated the maximum distance $\left(D_{\max }\right)$ among size-frequency distributions where $D_{\max }=$ $\max i\left|y_{i 1}-y_{i 2}\right|$. Here the absolute value of $y_{i 1}-y_{i 2}$ reflects the observed difference in abundance for each size class. We conducted a 1-way permutational ANOVA for the factor management zone in the PERMANOVA routine, using $9 \times 10^{5}$ unrestricted permutations of the raw data to conduct an exact test and pairwise comparisons using Monte-Carlo p-values, which are valid when the possible number of unique permutations is low.

Potential egg production. The size-frequency distribution of females at each site was combined with a size-specific fecundity equation used for the Fiordland rock lobster fishery $\left(f=0.0567 \mathrm{CL}^{3.18}\right.$; after Annala \& Bycroft 1987) to estimate the potential number of eggs produced $250 \mathrm{~m}^{-2} \mathrm{yr}^{-1}$ at each of the 8 sites for mature females. Estimates of egg production $250 \mathrm{~m}^{-2} \mathrm{yr}^{-1}$ were compared among the 3 marine reserves and the CEZ. Because there was a low number of sites per group ( $\mathrm{n}=2$ ), we calculated Euclidean distances among sites and conducted a 1-way permutational ANOVA in the PERMANOVA routine as described above.

\section{RESULTS}

\section{Fiordland-wide abundance of red rock lobster}

There were significant differences $\left(F_{3,144}=13.37, \mathrm{p}<\right.$ 0.001 ) in the abundance of rock lobsters among management zones across Fiordland (Fig. 4). A post hoc Tukey's test revealed that in marine reserves established in 1993, lobster density was significantly higher than in all other management zones (Fig. 4).

\section{Videogrammetry: development and testing}

The equation derived from the morphometric data $(\mathrm{CL}=38.207+3.364$ SOS $)$ predicted CL from SOS with $>95 \%$ accuracy $(R[x]=0.954)$. No difference was detected between 30 measures of CL derived using the regression equation and measurements made with Vernier calipers at the $\alpha=0.05$ level. Partitioning of the variance showed that $6.28 \%$ of the total variance in CL was explained by the within-lobster component, whilst $93.72 \%$ was due to inter-individual variations in the trait. No difference was detected between 32 estimates of CL by experienced and novice users of the method at the $\alpha=0.05$ level. No difference was detected at the $\alpha=0.05$ level between visual estimates made by divers with the videogrammetric system in 2007. However, in 2008 the 2 estimates differed significantly, with divers assigning a greater proportion of the population to the largest size class (Fig. 5).

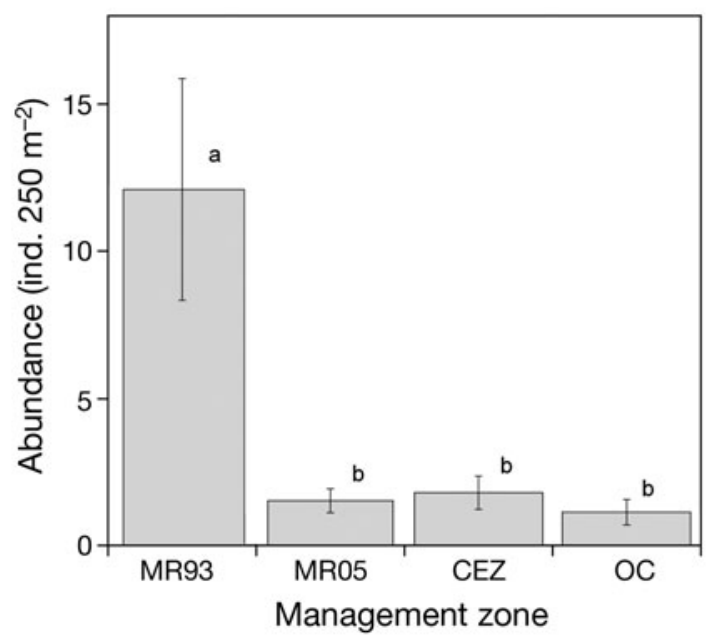

Fig. 4. Jasus edwardsii. Relative abundances of red rock lobsters in Fiordland at sites in marine reserves established in 1993 (MR93) ( $\mathrm{n}=4)$ and 2005 (MR05) $(\mathrm{n}=10)$, in commercial exclusion zones (CEZ) $(n=8)$ and on the open coast (OC) $(\mathrm{n}=4)$. Error bars are \pm 1 SE. Management zones with different letters are significantly different 


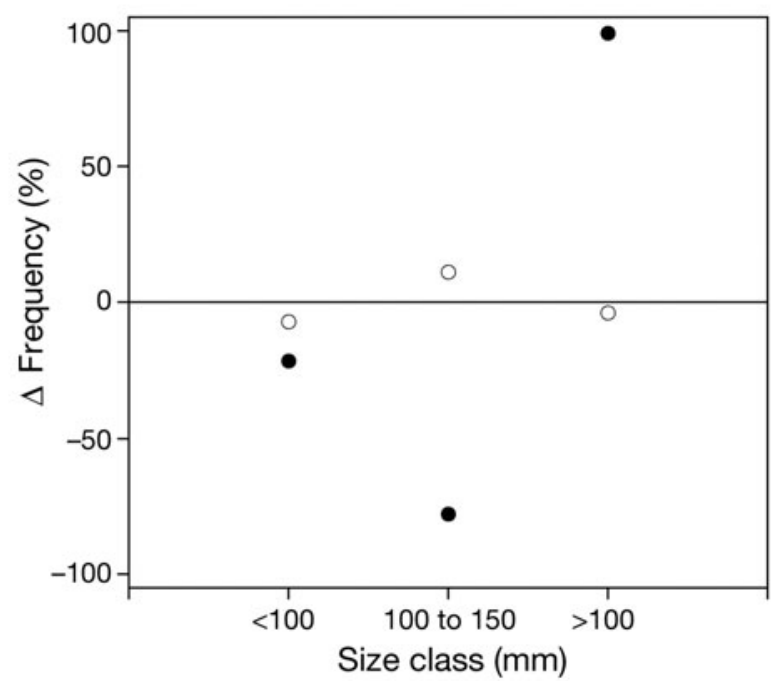

Fig. 5. Jasus edwardsii. Differences between underwater visual census (UVC) and videogrammetry estimates of the proportion of red rock lobsters in 3 size categories $(<100,100$ to 150 and $>150 \mathrm{~mm}$ carapace length; $\Delta=$ video grammetric-UVC) in 2007 (O) and 2008

\section{Red rock lobster population structure}

No differences were found in the size-frequency distribution of males among management zones at the $\alpha=$ 0.05 level. However, the size-frequency distribution of female lobsters did differ among management zones (pseudo- $F=7.3294$, df $=2$; Monte-Carlo $\mathrm{p}=0.00448$, 15 unique permutations; pairwise comparisons: Te Awaatu Channel [a], Kutu Parera marine reserve [ab], CEZ [b], at the $\alpha=0.05$ level). Overall, greater relative abundance and a more mature age structure, including high abundance of legal-sized females, were observed at Te Awaatu Channel compared with other regions (Fig. 6a). At Kutu Parera marine reserve we found an intermediate relative abundance of lobsters and a mature age structure with a large proportion of large females (Fig. 6b). At sites in the CEZ we found lower densities of lobsters and lower frequencies of large females (Fig. 6c).

\section{Potential egg production}

In the 3 regions where lobsters were found, the variation in sex ratio and population maturity/age structure were used to estimate potential fecundity in each management zone (Fig. 7). Overall, the potential egg production for rock lobsters differed among the 4 management zones (pseudo- $F=26.554$, df $=3$; permutational-p $=0.0094,60$ unique permutations). Egg production was greatest in the Te Awaatu Channel marine reserve, low in the CEZ and intermediate in the Kutu
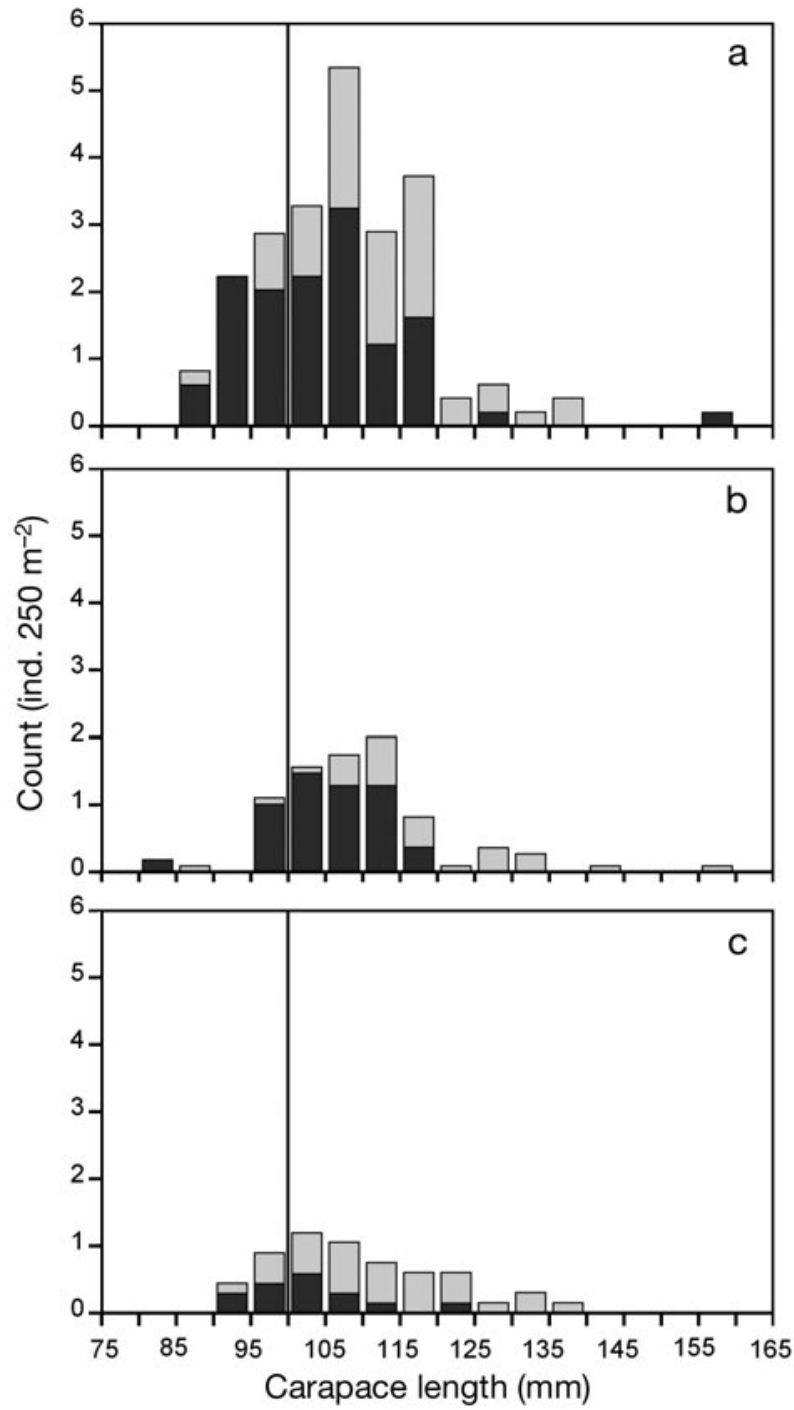

Fig. 6. Jasus edwardsii. Size-frequency distributions of male (light grey) and female (dark grey) red rock lobster from videogrammetric data at (a) Te Awaatu Channel marine reserve, (b) Kutu Parera marine reserve and (c) commercial exclusion zone sites. Vertical line indicates minimum legal size $(\approx 100 \mathrm{~mm} \mathrm{CL})$

Parera marine reserve. Estimated production was zero at the Taipari Roa marine reserve (pairwise comparisons: Taipari Roa [c], CEZ [b], Kutu Parera marine reserve [ab], Te Awaatu Channel [a] at the $\alpha=0.05$ level) (Fig. 8).

\section{DISCUSSION}

Recovery of mature age structure and abundance of exploited populations within marine reserves offers distinct gains for fishery enhancement and sustainability across complex coastlines. In the present study we 

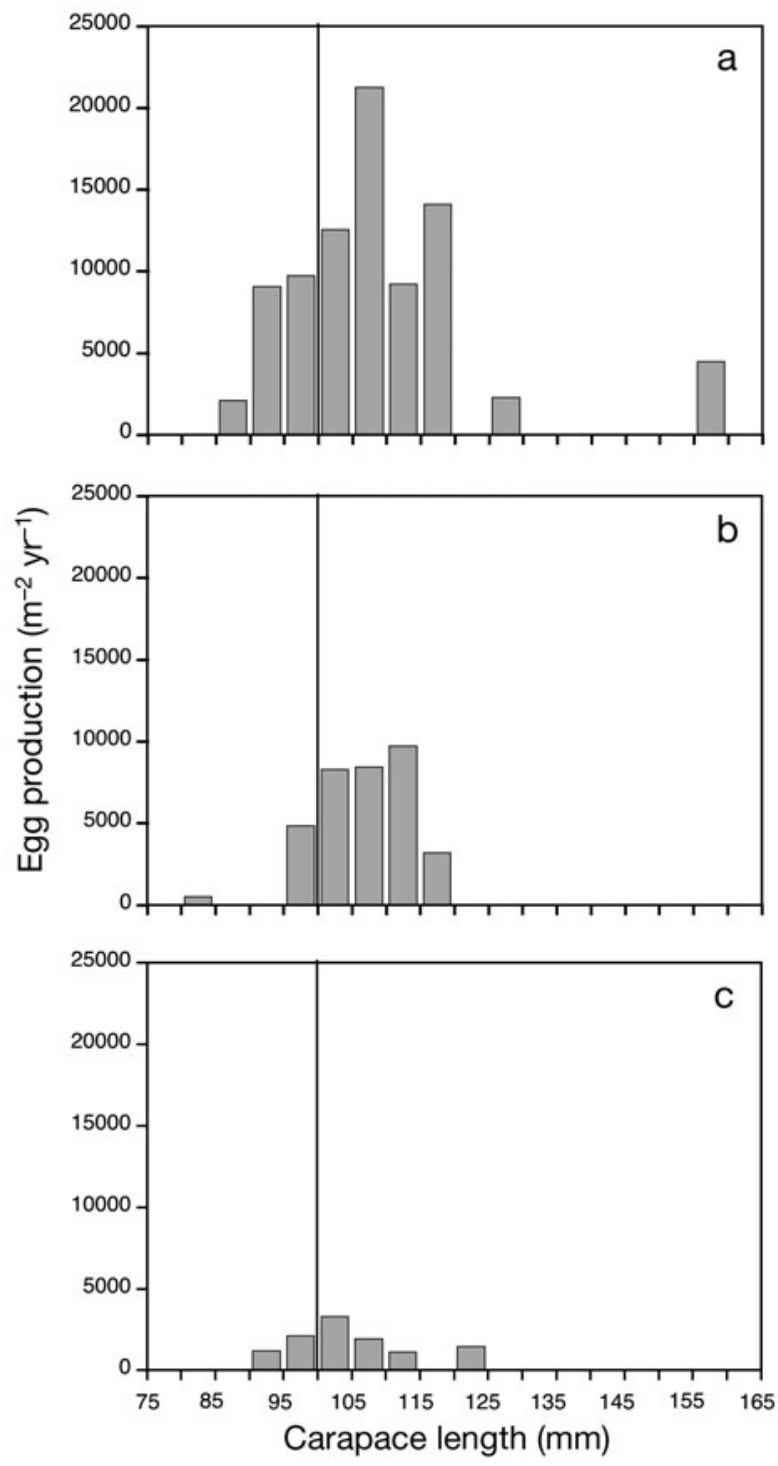

Fig. 7. Jasus edwardsii. Fecundity (egg production) on rocky reef habitat of female red rock lobster at (a) Te Awaatu Channel marine reserve, (b) Kutu Parera marine reserve and (c) commercial exclusion zone sites. Vertical line indicates minimum legal size ( $\approx 100 \mathrm{~mm}$ carapace length)

described variation in abundance and size structure of the red rock lobster Jasus edwardsii across a newly created network of marine protected areas in the Fiordland Marine Area. Here, patterns in abundance and size structure are likely driven by the interplay between habitat quality and spatial management zones, with implications for source-sink structure and contributions to the regional larval pool. Populations under the greatest level of protection from fishing and in high quality habitats were the most fecund. Development of mature population size structures was truncated in the regions where recreational fishing was

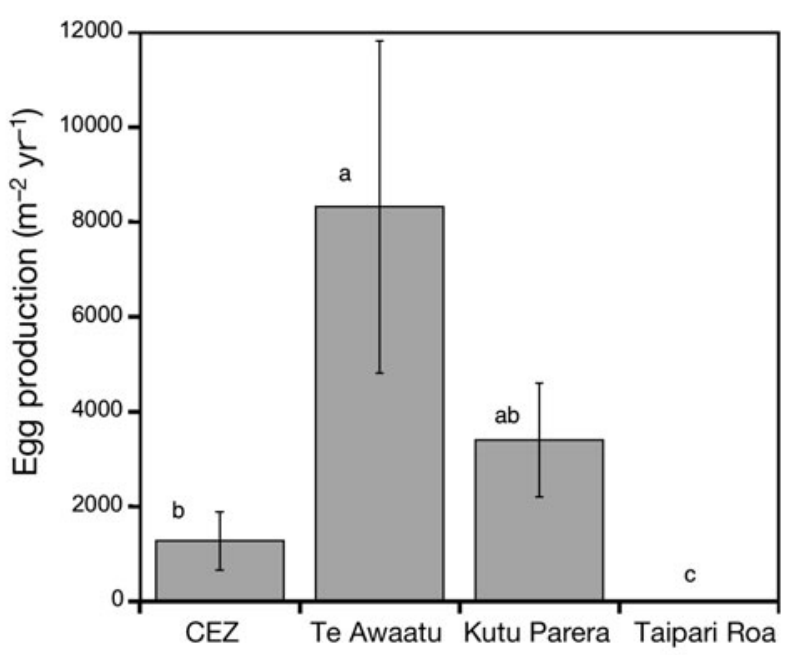

Fig. 8. Jasus edwardsii. Relative potential egg production of red rock lobster on rocky reef habitat at the Te Awaatu Channel, Kutu Parera and Taipari Roa marine reserves and in the commercial exclusion zone (CEZ). Error bars are \pm 1 SE. Management zones with different letters are significantly different

allowed or habitat was degraded, so that potential contributions to the larval pool from these regions were relatively low.

Measurement of size-frequency distributions within marine protected areas with sufficient accuracy and precision to resolve differences in size-specific fecundity requires a non-intrusive and repeatable method for measuring size of lobsters in the field. Though size estimates from visual underwater surveys are easily obtained, variability among researchers was shown to be large and resolution of size classes was too coarse to provide reliable estimates of size-specific fecundity. In the present study we developed a photogrammetric technique that enabled resolution of rock lobster CL in the field with a high degree of accuracy and precision. This, coupled with the advantages of a permanent record of each measurement, provided a non-intrusive method that can be used for monitoring populations in marine reserves with enough precision to resolve differences in fecundity and changes in size-frequency distributions over time.

Increases in animal abundances and sizes in marine reserves likely translates into increased reproductive potential, provided there are not large differences in onset of maturity (Goni et al. 2003), mate selection (MacDiarmid \& Butler 1999) or other environmentally driven influences on fecundity (Pollock 1995). The results of the present study demonstrate that at the landscape scale in Fiordland, the highest densities and most mature size distributions of red rock lobsters are contained within well-established marine 
reserves. These data are consistent with observations that local cessation of fishing mortality may result in buildup of high densities of red rock lobsters in marine reserves (Pande et al. 2008). Observations from other systems indicate that size-specific egg production in rock lobsters might be enhanced in marine reserves due to earlier onset of maturity (Goni et al. 2003) and enhanced mate choice (MacDiarmid \& Butler 1999). However, poor quality habitat and poor nutrition has the potential to reduce these effects (Pollock 1995). We did not detect a regional effect of reserves established 1 to 2 yr before data collection, which was not unexpected because reserve effects can be correlated with reserve age (Kelly et al. 2000, Claudet et al. 2008) and the new reserves are distributed across a range of habitat types with varying attributes (Rodwell et al. 2003; although Kelly et al. 2000 reported increases in Jasus edwardsii egg production of $9.1 \%$ per year of protection among 3 northern New Zealand reserves). Examination of size distributions and sex ratios of red rock lobsters in the Doubtful-Bradshaw Sound complex, where the largest variability in abundance among management zones was observed, revealed that the highest density and most mature size structure of lobsters occurred in the Te Awaatu Channel marine reserve (est. 1993). Lower densities and slightly fewer large females were observed within the newly established Kutu Parera marine reserve (est. 2005). Both low densities and a more truncated size distribution were found at the sites within the CEZ, whilst rock lobsters were absent from the Taipari Roa marine reserve (est. 2005), where habitat and food resources have been degraded.

Unlike other species of spiny lobsters, Jasus edwardsii only produce one brood per year (Quackenbush 1994). Fecundity of $J$. edwardsii increases geometrically with CL of females through increases in eggs produced per brood (Annala \& Bycroft 1987). Our estimation of fecundity patterns per unit area among management zones in the Doubtful-Bradshaw Sound complex demonstrates the importance of both abundance and maturity of size distributions on potential egg production for this species. The estimate of fecundity per unit area of rocky reef in the Te Awaatu Channel marine reserve $\left(\sim 2.6 \times 10^{6}\right.$ eggs $\left.250 \mathrm{~m}^{-2} \mathrm{yr}^{-1}\right)$ was 8 times higher than in the CEZ $(\sim 3.2 \times$ $10^{5}$ eggs $\left.250 \mathrm{~m}^{-2} \mathrm{yr}^{-1}\right)$, and 3 times as high as in the newly established Kutu Parera marine reserve $(\sim 8.5 \times$ $10^{5}$ eggs $250 \mathrm{~m}^{-2} \mathrm{yr}^{-1}$ ).

These data are consistent with strong effects of both management regime and habitat quality on the population structure and resultant reproductive capacity of rock lobsters across the DoubtfulBradshaw Sound complex. In the Te Awaatu Channel marine reserve, we propose that both high quality habitat and sustained protection from fishing have resulted in the buildup of a mature size structure of male and female lobsters. In spite of potential positive effects of similarly high habitat quality, at sites in the adjacent CEZ we described patterns consistent with a strong influence of recreational fishing, which has truncated the population structure by selective removal of large individuals. Fishing pressure at these sites is perhaps exacerbated by their proximity to a renowned marine reserve. In the newly established Kutu Parera marine reserve, patterns in population structure are consistent with inner-fjord habitat of sufficient quality to support high biomass and a mature size structure that is protected from recreational fishing. This habitat quality may be characterised by beds of abundant mussels (predominantly Mytilus edulis galloprovincialis) (Jack et al. 2009). Results from the present study indicate an absence of rock lobsters at Taipari Roa, where amelioration of fishing pressure in this newly established marine reserve is likely insufficient to override the negative effects of localised habitat degradation.

Larger no-take zones have been shown to harbour higher densities of fished species (Claudet et al. 2008). The marine reserves in the Doubtful-Bradshaw Sound complex differ considerably in size. However, the observed patterns in rock lobster population structure are unlikely driven by these differences, as Te Awaatu marine reserve is the smallest (93 ha), Taipari Roa is the largest (613 ha) and Kutu Parera is of intermediate size (433 ha). A positive relationship between reserve size and population structure is contrary to the observed trend. As red rock lobsters typically inhabit crevices and caves (MacDiarmid 1991, Annala \& Bycroft 1993), the observed patterns may also be driven by differences in available physical habitat among regions. Although the present study has not directly quantified rocky reef habitat in each region, we note that ample unoccupied crevices were seen at all sites, including in the Taipari Roa marine reserve.

The described spatial variability in fecundity on rocky reef habitat has likely implications for the success of the newly implemented Fiordland marine protected area network in conserving self-sustaining populations within reserves, supporting viable regional metapopulation structure and enhancing the larval pool at a landscape scale. Scales of spillover from marine reserves vary across species and ecosystems from 100s of metres to 100s of kilometres (Roa \& Bahamonde 1993, McClanahan \& Mangi 2000, Kelly 2001). Jasus edwardsii has the longest known larval duration of any spiny lobster at 12 to 24 mo (Booth 1994), and the potential for locally productive regions to provide sources of recruits for distant populations 
is particularly strong in this species. Although resolving the link between local fecundity and regional recruitment is beyond the scope of the present study, the Fiordland red rock lobster stock has been identified as a major source of recruitment for a large segment of the New Zealand rock lobster population, likely providing between 74 and $95 \%$ of larvae that eventually settle in the surrounding fisheries of the South Island (Chiswell \& Booth 2008). Populations of lobsters in suitable habitat that are protected from fishing have the potential to develop high abundances and mature age structures and may contribute disproportionately to the larval pool, with potentially far reaching and disproportionate implications for recruitment in adjacent regions. The Te Awaatu and Kutu Parera marine reserves show potential to support highly fecund populations of $J$. edwardsii, whereas the degraded habitat in the Taipari Roa marine reserve will likely support very low or no egg production.

Maintenance of high potential fecundity on rocky reef habitat among local populations of red rock lobsters requires high abundances as well as mature size distributions (Andrew \& MacDairmid 1991). The present study provides evidence that, compared with other management zones, these criteria are most adequately met within marine reserves in Fiordland, but are likely strongly influenced by length of time of protection and local habitat quality within the reserves (Jack et al. 2009). At sites where the habitat is degraded, amelioration of fishing pressure has a limited impact against local environmental forcing of vital rates. Under the adaptive management paradigm, reserve boundaries could be shifted to accommodate this knowledge and maximise the positive gains in terms of protecting exploited species such as rock lobsters of forfeiting space for reserves. The effect of doing so would likely be substantial gains in terms of fecundity of Jasus edwardsii per unit area on rocky reef habitat occupied by reserves and would likely have positive effects on the New Zealand red rock lobster population through increases in egg production in a key reproductive source region.

\section{LITERATURE CITED}

Allison G, Lubchenco J, Carr M (1998) Marine reserves are necessary but not sufficient for marine conservation. Ecol Appl 8(Suppl):79-92

Andrew NL, MacDairmid AB (1991) Interrelations between sea urchins and spiny lobsters in northeastern New Zealand. Mar Ecol Prog Ser 70:211-222

Annala J (1993) New Zealand rock lobster: biology and fishery. Fisheries Research Division, Report No 42, Wellington

Annala JH, Bycroft BL (1987) Fecundity of the New Zealand red rock lobster Jasus edwardsii. NZ J Mar Freshw Res 21:591-597
Annala JN, Bycroft BL (1993) Movements of rock lobsters tagged in Fiordland, New Zealand. NZ J Mar Freshw Res 27:183-190

Bailey RC, Byrnes J (1990) A new, old method for assessing measurement error in both univariate and multivariate morphometric studies. Syst Zool 39:124-130

Bantham E (1965) Rocky shore ecology of a New Zealand fjord. Trans R Soc NZ 6:215-227

> Bergeron P (2007) Parallel lasers for remote measurements of morphological traits. J Wildl Manag 71:289-292

> Berkeley S, Chapman C, Sogard S (2004) Maternal age as a determinant of larval growth and survival in a marine fish, Sebastes melanops. Ecology 85:1258-1264

> Birkeland C, Dayton P (2005) The importance in fishery management of leaving the big ones. Trends Ecol Evol 20:356-358

Booth J (1994) Jasus edwardsii larval recruitment off the east coast of New Zealand. Crustaceana 66:295-317

Botsford LW, Malloney CL, Largier JL, Hastings A (1998) Metapopulation dynamics of meroplanktonic invertebrates: the Dungeness crab (Cancer magister) as an example. Can Spec Publ Fish Aquat Sci 125:295-306

Boyle MC, Jillett JB, Mladenov PV (2001) Intertidal communities in Doubtful Sound New Zealand: changes over time. NZ J Mar Freshw Res 35:663-673

Chiswell SM, Booth JD (2008) Sources and sinks of larval settlement in Jasus edwardsii around New Zealand: Where do larvae come from and where do they go? Mar Ecol Prog Ser 354:201-217

Claudet J, Osenberg C, Benedetti-Cecchi L, Domenici P and others (2008) Marine reserves: size and age do matter. Ecol Lett 11:481-489

Cornelisen CD, Wing SR, Clark KL, Bowman MH (2007) Patterns in $\delta^{13} \mathrm{C}$ and $\delta^{15} \mathrm{~N}$ signatures of Ulva pertusa: interaction between physical gradients and nutrient source pools. Limnol Oceanogr 52:820-832

Dayton PK, Sala E, Tegner MJ, Thrush S (2000) Marine reserves: parks, baselines and fishery enhancement. Bull Mar Sci 66:617-634

Durban JW, Parsons KM (2006) Laser-metrics of free-ranging killer whales. Mar Mamm Sci 22:735-743

Edgar GJ, Stewart-Smith RD (2009) Ecological effects of marine protected areas on rocky reef communities-a continental-scale analysis. Mar Ecol Prog Ser 388:51-62

Edgar GJ, Barrett NS, Morton AJ (2004) Biases associated with the use of underwater visual census techniques to quantify the density and size-structure of fish populations. J Exp Mar Biol Ecol 308:269-290

English S, Wilkinson C, Baker V (1994) Survey manual for tropical marine resources, Vol 1. Australian Institute of Marine Science, Townsville

Fairbairn DJ (1997) Allometry for sexual size dimorphism: pattern and process in the coevolution of body size in males and females. Annu Rev Ecol Syst 28:659-687

- Fleishman E, Ray C, Sjogren-Gulve O, Bloggs C, Murphy D (2002) Assessing the roles of patch quality, area and isolation in predicting metapopulation dynamics. Conserv Biol 16:706-716

> Fogarty M (1999) Essential habitat, marine reserves and fisheries management. Trends Evol Ecol 14:133-134

Gingras ML, Ventresca DA, McGonigal RH (1998) In-situ videography calibrated with 2 parallel lasers for calculation of fish length. Calif Fish Game 84:36-39

> Goni R, Quetglas A, Reñones O (2003) Size at maturity, fecundity and reproductive potential of a protected population of the spiny lobster Palinurus elephas (Fabricius, 1787) from the western Mediterranean. Mar Biol 143:583-592 
Halpern B (2003) The impact of marine reserves: Do they work and does size matter? Ecol Appl 13(Suppl):117-137

Hanski I, Gyllenberg M (1993) Two general metapopulation models and the core-satellite species hypothesis. Am Nat 142:17-41

Harvey E (2000) A comparison of the precision and accuracy of estimates of reef-fish lengths determined visually by divers with estimates produced by a stereo-video system. Fish Bull 99:63-71

Hastings A, Botsford LW (1999) Equivalence in yield from marine reserves and traditional fisheries management. Science 284:1537-1538

Jack L, Wing SR, McLeod RJ (2009) Prey base shifts in red rock lobster Jasus edwardsii in response to habitat conversion in Fiordland marine reserves: implications for effective spatial management. Mar Ecol Prog Ser 381: 213-222

Kelly S (2001) Temporal variation in the movement of the spiny lobster Jasus edwardsii. Mar Freshw Res 52: 323-331

> Kelly S, Scott D, MacDiarmid AB, Babcock RC (2000) Spiny Lobster, Jasus edwardsii, recovery in New Zealand marine reserves. Biol Conserv 92:359-369

Kritzer JP, Sale PF (eds) (2006) Marine metapopulations. Elsevier Academic Press, Oxford

> Langlois TJ, Anderson MJ, Babcock RC (2005) Reef associated predators influence adjacent soft-sediment communities. Ecology 86:1508-1519

Lindholm J, Auster P, Ruth M, Kaufman L (2001) Modelling the effects of fishing and implications for the design of marine protected areas: juvenile fish responses to variations in seafloor habitat. Conserv Biol 15:424-437

Love M, Caselle J, Snook L (2000) Fish assemblages around seven oil platforms in the Santa Barbara Channel area. Fish Bull 98:96-117

MacArthur R, Wilson E (1967) The theory of island biogeography. Princeton University Press, Princeton, NJ

MacDiarmid AB (1991) Seasonal changes in depth distribution, sex ratio and size frequency of spiny lobster Jasus edwardsii on a coastal reef in northern New Zealand. Mar Ecol Prog Ser 70:129-141

MacDiarmid AB, Breen PA (1992) Spiny lobster population change in a marine reserve

MacDiarmid A, Butler M (1999) Sperm economy and limitation in spiny lobsters. Behav Ecol Sociobiol 46:14-24

McClanahan T, Mangi S (2000) Spillover of exploitable fishes from a marine park and its effect on the adjacent fishery. Ecol Appl 10:1792-1805

McLeod RJ, Wing SR (2007) Hagfish populations in the New Zealand fjords are supported by chemoautotrophy of forest litter carbon. Ecology 88:809-816

McLeod RJ, Wing SR (2008) Influence of an altered salinity regime on the population structure of two infaunal bivalve species. Estuar Coast Shelf Sci 78:529-540

Palumbi S (2001) The ecology of marine protected areas. In: Bertness M, Gaines S, Hay M (eds) Marine community ecology. Sunderland, Boston, MA, p 509-530

Pande A, MacDiarmid AB, Smith PJ, Davidson RJ and others (2008) Marine reserves increase the abundance and size of blue cod and rock lobster. Mar Ecol Prog Ser 366: $147-158$

Pollock D (1995) Changes in maturation ages and sizes in crustacean and fish populations. S Afr J Mar Sci 15:99-103

> Quackenbush L (1994) Lobster reproduction: a review. Crustaceana 67:82-94

Quinn J, Wing SR, Botsford L (1993) Harvest refugia in marine invertebrate fisheries: models and applications to the red sea urchin, Strongylocentrotus franciscanus. Am Zool 35:537-550

Roa R, Bahamonde R (1993) Growth and expansion of an exploited population of the squat lobster (Pleuroncodes monodon) after 3 years without harvesting. Fish Res 18:305-319

Roberts CM, Polunin NVC (1991) Are marine reserves effective in the management of reef fisheries? Rev Fish Biol Fish 1:65-91

Roberts CM, Bohnsack JA, Gell F, Hawkins JP, Goodridge R (2001) Effects of marine reserves on adjacent fisheries. Science 294:1920-1923

Rochet MJ, Cadiou JF, Trenkel VM (2003) Precision and accuracy of fish length measurements obtained with two visual underwater methods. Fish Bull 104:1-9

$>$ Rodgers KL, Wing SR (2008) Spatial structure and movement of blue cod Parapercis colias in Doubtful Sound, New Zealand, inferred from $\delta^{13} \mathrm{C}$ and $\delta^{15} \mathrm{~N}$. Mar Ecol Prog Ser 359:239-248

> Rodwell LD, Barbier EB, Roberts CM, McClanahan TR (2003) The importance of habitat quality for marine reservefishery linkages. Can J Fish Aquat Sci 60:171-181

> Rogers-Bennett L, Leaf R (2006) Elasticity analysis of sizebased red and white abalone matrix models: management and conservation. Ecol Appl 16:213-224

Root K (1998) Evaluating the effects of habitat quality, connectivity, and catastrophes on a threatened species. Ecol Appl 8:854-865

Russ GR, Alcala AC (1996) Do marine reserves export adult fish biomas? Evidence from Apo Island, central Philippines. Mar Ecol Prog Ser 132:1-9

> Rutger SM, Wing SR (2006) Effects of freshwater input on shallow-water infaunal communities in Doubtful Sound, New Zealand. Mar Ecol Prog Ser 314:35-47

Salomon AK, Shears NT, Langlois TJ, Babcock RC (2008) Cascading effects of fishing can alter carbon flow through a temperate coastal ecosystem. Ecol Appl 18:1874-1887

Sanford E, Menge BA (2007) Reproductive output and consistency of source populations in the sea star Pisaster ochraceus. Mar Ecol Prog Ser 349:1-12

> Shears NT, Babcock RC (2002) Marine reserves demonstrate top-down control of community structure on temperate reefs. Oecologia 132:131-142

Shortis M, Harvey E, Abo D (2009) A review of underwater stereo-image measurement for marine biology and ecology applications. Oceanogr Mar Biol Annu Rev 47: 257-292

Starr P, Bentley N (2002) Assessment of the NSS stock of red rock lobster (Jasus edwardsii) for 1999. Ministry of Fisheries, Wellington

Tallis H, Wing SR, Frew R (2004) Historical evidence for habitat conversion and local population decline in a $\mathrm{New}$ Zealand fjord. Ecol Appl 14:546-554

> Willis TJ, Millar RB, Babcock RC (2000) Detection of spatial variability in relative density of fishes: comparison of visual census, angling, and baited underwater video. Mar Ecol Prog Ser 198:249-260

Willis TJ, Millar RB, Babcock RC (2003) Protection of exploited fish in temperate regions: high density and biomass of snapper Pagrus auratus (Sparidae) in northern New Zealand marine reserves. J Appl Ecol 40:214-227

Wing SR (2009) Decadal-scale dynamics of sea urchin population networks in Fiordland, New Zealand are driven by juxtaposition of larval transport against benthic productivity gradients. Mar Ecol Prog Ser 378:125-134

Wing SR (2010) Population networks with sources and sinks along productivity gradients in the Fiordland Marine 
Area, New Zealand: a case study on the sea urchin, Evechinus chloroticus. In: Lui J (ed) Sources, sinks and sustainability. Cambridge University Press (in press)

Wing SR, Gibbs MT, Lamare MD (2003) Reproductive sources and sinks within the sea urchin, Evechinus chloroticus, population of a New Zealand fjord. Mar Ecol Prog Ser 248:109-123

Wing SR, Leichter JJ, Perrin C, Rutger SM, Bowman MH, Cornelisen CD (2007) Topographic shading and wave exposure influence morphology and ecophysiology of

Editorial responsibility: Hans Heinrich Janssen, Oldendorf/Luhe, Germany
Ecklonia radiata (C. Agardh 1817) in Fiordland, New Zealand. Limnol Oceanogr 5:1853-1864

Wing SR, McLeod RJ, Clark KL, Frew RD (2008) Plasticity in the diet of two echinoderm species across an ecotone: microbial recycling of forest litter and bottom-up forcing of population structure. Mar Ecol Prog Ser 360: $115-123$

Witman JD, Grange KR (1998) Links between rain, salinity and predation in a rocky subtidal community. Ecology 79:2429-2447

Submitted: October 7, 2009; Accepted: January 20, 2010 Proofs received from author(s): March 19, 2010 